\title{
Chemical Constituents and an Alternative Medicinal Veterinary Herbal Soap Made from Senna macranthera
}

\author{
Flávia Inoue Andrade, ${ }^{1}$ Gislaine Aparecida Purgato, ${ }^{1}$ Thalita de Faria Maia, ${ }^{1}$ \\ Raoni Pais Siqueira, ${ }^{1}$ Sâmia Lima, ${ }^{1}$ Gaspar Diaz, ${ }^{2}$ and Marisa Alves Nogueira Diaz ${ }^{1}$ \\ ${ }^{1}$ Departamento de Bioquímica e Biologia Molecular, Universidade Federal de Viçosa, 36570-000 Viçosa, MG, Brazil \\ ${ }^{2}$ Departamento de Química, Universidade Federal de Minas Gerais, 31270-901 Belo Horizonte, MG, Brazil \\ Correspondence should be addressed to Marisa Alves Nogueira Diaz; marisanogueira@ufv.br
}

Received 23 October 2014; Accepted 14 February 2015

Academic Editor: Jenny M. Wilkinson

Copyright (C) 2015 Flávia Inoue Andrade et al. This is an open access article distributed under the Creative Commons Attribution License, which permits unrestricted use, distribution, and reproduction in any medium, provided the original work is properly cited.

\begin{abstract}
Upon undergoing biomonitoring, the most active dichloromethane extract retrieved from Senna macranthera roots led to the isolation of three main compounds: emodine, physione, and chrysophanol. In this sequence, these compounds revealed a potential antibacterial activity against Staphylococcus aureus strains isolated from animals with mastitis infections with minimum inhibitory concentration (MIC) values of 20, 90 , and $90 \mu \mathrm{g} \mathrm{mL}^{-1}$, respectively. Therefore, an herbal soap was also produced from this same active extract. This soap was tested in vitro using gloves contaminated by animals with bovine mastitis that had been discarded after use by milkers and showed similar results to previously tested compounds. These results indicate the potential of this plant as an alternative veterinary medicine for the production of antibacterial soaps that aimed at controlling bovine mastitis infections in small Brazilian farms.
\end{abstract}

\section{Introduction}

In Brazil, the use of medicinal plants contributes significantly to primary health care. These vegetation species are used in the form of crude extracts, infusions, or plasters to treat common infections in humans and animals [1]. The alternative use of medicinal plants to treat common infections in animals is increasing, as is knowledge in ethnoveterinary studies, especially in some regions of developing countries that have limited access to conventional medicines for animal health care, as they are often unaffordable to poor rural farmers [2].

Plants are rich in a wide variety of secondary metabolites, such as tannins, terpenoids, alkaloids, anthraquinones, and flavonoids, among other compounds, which have demonstrated in vitro antimicrobial properties. Of this wide variety of secondary metabolites, the anthraquinones have proven to be outstanding due to their broader action against several microorganisms [3]. These compounds are mainly found in Senna macranthera (Collad. Irwin et Barn) species, also known, by Brazilian local farmers, as pau fava and fedegoso, which belongs to the Fabaceae family. It is a native plant from Brazil that is commonly found in forests and is used as an ornamental tree. However, the Senna genus is also widely distributed in tropical and subtropical regions throughout the world, and it has been extensively, chemically, and pharmacologically investigated [4]. Folk medicine in Brazil has made use of these species (Fedegoso and Senna) as a remedy for various diseases, especially to treat infectious diseases [2]. The aerial parts and roots of $S$. macranthera have been used by some farmers to treat bovine mastitis, a chronic infection that produces an inflammatory response in cow's udders and that is caused by Staphylococcus aureus, the main etiologic causative agent of this disease. Staphylococci cause chronic infections due to their ability to adhere to many types of surfaces, in turn developing a matrix-encased community of cells, called biofilms, which hinders antibiotic action [5]. Therefore, the search for new antibiotics for the treatment of bovine mastitis must focus on inhibiting biofilm formation by plants or active compounds. Thus, this work aimed to test the bioassay-guided isolation compounds responsible for antibacterial activity and to check the effect of plant extracts 
on biofilm formation. This study also sought to produce an herbal soap from the active extract of $S$. macranthera and assess its antiseptic potential for alternative uses in veterinary medicine, especially with regard to the treatment of bovine mastitis at small farms in rural areas in Brazil.

\section{Materials and Methods}

2.1. General. Silica gel (70-230 mesh) and glass columns were used for column chromatography. All of the solvents used were of analytical grade. The melting point was determined using a Thermopan apparatus (C. Reichest Optische Wercke $\mathrm{A} \mathrm{G}) .{ }^{1} \mathrm{H}$ and ${ }^{13} \mathrm{C}$ nuclear magnetic resonance (NMR) spectra were recorded on $300 \mathrm{MHz}$ and $75 \mathrm{MHz}$ NMR spectrometers, respectively, (Mercury 300 spectrometer). Tetra methylsilane (TMS) was used as an internal standard. The IR spectra were measured in a Perkin Elmer Paragon 1000 FTIR spectrophotometer, using potassium bromide $(1 \% \mathrm{w} / \mathrm{w})$ scanning from 400 to $4000 \mathrm{~cm}^{-1}$.

2.2. Plant Material. S. macranthera was collected from Violeira, a neighborhood located $\left(20^{\circ} 44^{\prime} 5^{\prime \prime} \mathrm{S}, 40^{\circ} 51^{\prime} 26^{\prime \prime} \mathrm{W}\right)$ in Viçosa, MG, Brazil, in February 2011, and an authenticated voucher (VIC 39644) was deposited in the university's herbarium. The roots were dried at $40^{\circ} \mathrm{C}$ in an air circulation oven. Dried roots $(800 \mathrm{~g})$ were extracted using $n$-hexane, dichloromethane, and ethanol for 5 days each and repeated at least five times. The solvents were concentrated under reduced pressure until they were completely dry, and the extracts were stored at $4^{\circ} \mathrm{C}$.

2.3. Phytochemical Studies. The active dichloromethane extract from the $S$. macranthera roots was first subjected to a chromatography column, using dichloromethane as the eluent. The eluent polarity was then gradually increased by adding ethyl acetate, yielding 50 fractions. The fractions obtained were subsequently submitted to biological assay using the $S$. aureus strain 3828 (identified by the Embrapa Dairy Cattle from the Milk Microbiology Laboratory) as an infectious reference microorganism. The bioassayed positive fractions were submitted to a preparative thin layer chromatography (PTLC) eluted with dichloromethane/EtOAc $(8: 2)$, allowing for the isolation of three compounds: 1 (6 mg), 2 (4 mg), and 3 (5 mg) (Figure 1).

2.4. Bacterial Strains and Culture Media. The bacterial strains used in this study, which were isolated from animals with mastitis infections, were kindly provided by the Embrapa Dairy Cattle from the Milk Microbiology Laboratory, (Juiz de Fora, MG, Brazil). Six Staphylococcus aureus strains (3828, $3893,4075,4125,4158$, and 4182) and Streptococcus agalactiae (3849), Streptococcus bovis (550), and Escherichia coli (24) bacteria (one strain of each) were used to determine the antimicrobial activity of the extracts, fractions, and isolated compounds. Bacteria were routinely cultured on brain heart infusion (BHI) agar at $37^{\circ} \mathrm{C}$ for $16 \mathrm{~h}$ before conducting the experiments. The cell concentration was adjusted to $10^{6} \mathrm{CFU} \mathrm{mL}^{-1}$ with an optical density set at $600 \mathrm{~nm}$. Stock cultures were maintained in BHI agar containing $25 \%$ glycerol at $-80^{\circ} \mathrm{C}$.

2.5. Antibacterial Screening Assay. Hole-plate diffusion assay was initially performed to test the antibacterial activity of the fractions obtained from crude extracts of the roots. To accomplish this, the bacteria were cultivated overnight, and a suspension containing $10^{6} \mathrm{CFU} \mathrm{mL}^{-1}$ was spread on plates containing Müeller-Hinton agar (Himedia). Holes of approximately $5 \times 3 \mathrm{~mm}$ were made in the agar and filled with $30 \mu \mathrm{L}$ of the fraction stock solutions $\left(50 \mathrm{mg} \mathrm{mL}^{-1}\right)$ and $10 \mu \mathrm{g} \mathrm{mL}^{-1}$ for compounds 1, 2, and 3. After incubation at $37^{\circ} \mathrm{C}$ for $24 \mathrm{~h}$, inhibition zones were measured in millimeters and compared to the controls. The antibiotic ciclopirox olamine (Uci-Farma) was used as the positive control due to its antibacterial properties [6]. Dimethylsulfoxide (DMSO) was used as a negative control. Tests were performed twice in triplicate. The minimum inhibitory concentration (MIC) of compounds 1, 2, and $\mathbf{3}$ was determined by applying a broth microdilution method followed by incubation at $37^{\circ} \mathrm{C}$ for $24 \mathrm{~h}$ and by observing media turbidity. Tests were performed twice in triplicate.

2.6. Effect of Plant Extracts on Cell Adherence. The effect of subinhibitory concentrations of active dichloromethane extract established biofilms was evaluated according to Nostro et al. [7] with few modifications. Bacterial suspensions were inoculated on microplates containing $180 \mu \mathrm{L}$ of $\mathrm{BHI}$ until reaching the final concentration of $10^{6} \mathrm{CFU} \mathrm{mL}^{-1}$ and incubated at $37^{\circ} \mathrm{C}$ for $24 \mathrm{~h}$. The supernatant was withdrawn; wells were washed three times with $0.85 \%$ saline and filled again with BHI containing different concentrations of the active extracts (MIC, 1/2 MIC, 1/4 MIC, 1/8 MIC, and $1 / 16 \mathrm{MIC}$ ), followed by incubation at $37^{\circ} \mathrm{C}$ for $24 \mathrm{~h}$. The biofilm inhibitory concentration (BIC) was defined as the concentration at which no visible microbial growth was observed. The assay was performed twice in triplicate.

2.7. Effect of Plant Extracts on Biofilm Formation. Bacterial suspensions were inoculated on microplates containing $180 \mu \mathrm{L}$ of $\mathrm{BHI}$ with different concentrations of the active extracts (MIC, 1/2 MIC, 1/4 MIC, 1/8 MIC, and 1/16 MIC) until reaching the final concentration of $10^{6} \mathrm{CFU} \mathrm{mL}^{-1}$ and incubated at $37^{\circ} \mathrm{C}$ for $24 \mathrm{~h}$. The supernatant was withdrawn and wells were washed three times with $0.85 \%$ saline. The remaining bacterial mass was dried at $37^{\circ} \mathrm{C}$ for $15 \mathrm{~min}$ and stained with $200 \mu \mathrm{L}$ of crystal violet $0.1 \%$ for $30 \mathrm{~min}$. Wells were rewashed and dried as previously described, followed by the addition of $300 \mu \mathrm{L}$ of ethanol and the measurement of absorbance at $630 \mathrm{~nm}$. The test was performed twice in triplicate.

2.8. Production of Herbal Soap. The active extract of $S$. macranthera (250 $\mathrm{mg}$ ) was incorporated into a soap produced according to its patent: 1005633-5 [8]. Later, the semi-solid mixture was poured into a mold and allowed to solidify. Soap without the extract was also produced to be used as a reference product. 
<smiles>COc1cc(O)c2c(c1)C(=O)c1cc(C)cc(O)c1C2=O</smiles>

FIGURE 1: Isolated compounds from the most active fraction of the Senna macranthera roots.

2.9. Antibacterial Assay of the Herbal Soap. The agar-dilution method was employed in an in vitro evaluation. The herbal soap $(1.0 \mathrm{~g})$ was dissolved in distilled water $(50 \mathrm{~mL})$ to obtain a $2 \%$ suspension. The suspension was vigorously shaken to dissolve the soap, to disperse the foam, and to homogenize the suspension. Next, $1.0 \mathrm{~mL}$ of the soap solution was added to $20 \mathrm{~mL}$ of sterile molten culture media in Petri dishes and allowed to set. One hundred $\mu \mathrm{L}$ of suspension containing $10^{6} \mathrm{CFU} \mathrm{mL}^{-1}$ of a resistant $3828 \mathrm{~S}$. aureus strain was then streaked on the plates. After incubation at $37^{\circ} \mathrm{C}$ for $24 \mathrm{~h}$, inhibition zones were compared to the control to observe the presence or absence of microbial growth.

Gloves contaminated with $S$. aureus from animals with mastitis infection were used to perform the in vivo evaluation (topical test according to our institutional ethical protocol number 773.182$)$. The herbal soap $(1.0 \mathrm{~g})$ was dissolved in distilled water $(100 \mathrm{~mL})$ to obtain a $1 \%$ suspension. This suspension was then vigorously shaken to dissolve the soap, to disperse the foam, and to homogenize it. Thereafter, the gloves (12 pairs, 6 for each control soap and herbal soap treatment) were immersed in these solutions for 30 minutes. Before being immersed in the soap, the gloves that the milkers had used to milk the cow's udder, which had been contaminated with $S$. aureus, were swabbed, and the sample was placed in bottles with sterile normal saline. After being immersed in both the herbal and control soaps, the gloves were again swabbed, and the samples were placed in separate bottles with normal sterile saline solution. Aliquots from the respective treatments were cultured on an agar plate at $37^{\circ} \mathrm{C}$ for $24 \mathrm{~h}$ to observe the presence or absence of microbial growth.

\section{Results and Discussion}

Purification of the most active fraction obtained from the bioassay-guided active dichloromethane extract from $S$. macranthera roots led to the isolation of three active compounds, which were characterized as emodine (1), physcione (2), and chrysophanol (3) (Figure 1).

Compound 1. It is an orange amorphous powder from $\mathrm{CHCl}_{3}, \mathrm{mp} 261-264^{\circ} \mathrm{C}$. The IR spectrum showed absorptions referring to a hydroxyl group $\left(3382 \mathrm{~cm}^{-1}\right)$ and carbonilic groups (1677 and $1627 \mathrm{~cm}^{-1}$, resp.). The EI mass spectrum of 1 displayed a molecular ion $[\mathrm{M}]^{+}$at $m / z 270(100 \%)$, which is in accordance with the molecular formula $\mathrm{C}_{15} \mathrm{H}_{10} \mathrm{O}_{5}$. Other major fragments were observed at $m / z 269$ and $241 .{ }^{1} \mathrm{H}$ NMR $\left(300 \mathrm{MHz}, \mathrm{CDCl}_{3}\right): \delta 2.42(3 \mathrm{H}, \mathrm{s}), 6.55(1 \mathrm{H}, \mathrm{d}, J=1.0 \mathrm{~Hz}$,
H-2), $7.08(1 \mathrm{H}, \mathrm{d}, J=1.0 \mathrm{~Hz}, \mathrm{H}-4), 7.17(1 \mathrm{H}, \mathrm{d}, J=2.4, \mathrm{H}-7)$, $7.55(1 \mathrm{H}, \mathrm{d}, J=2.4 \mathrm{~Hz}, \mathrm{H}-5), 12.08(1 \mathrm{H}, \mathrm{s}, \mathrm{H}-1), 12.28(1 \mathrm{H}, \mathrm{s}$, $\mathrm{H}-8) ;{ }^{13} \mathrm{C}$ NMR $\left(75 \mathrm{MHz}, \mathrm{CDCl}_{3}\right): \delta 21.2\left(\mathrm{C}-2^{\prime}\right), 106.7(\mathrm{C}-5)$, 108.9 (C-7), 162.2 (C-1), 167.3 (C-6), 184.3 (C-10), 192.3 (C-9).

Compound 2. It is an orange amorphous powder from $\mathrm{CDCl}_{3}, \mathrm{mp} 206-209^{\circ} \mathrm{C}$. The IR spectrum showed absorptions referring to a hydroxyl group $\left(3340 \mathrm{~cm}^{-1}\right)$ and carbonilic groups (1656 and $1619 \mathrm{~cm}^{-1}$, resp.). The EI mass spectrum of 2 displayed a molecular ion $[\mathrm{M}]^{+}$at $m / z 284(100 \%)$, which is in accordance with the molecular formula $\mathrm{C}_{16} \mathrm{H}_{12} \mathrm{O}_{5}$. Other major fragments were also observed at $m / z 269$ and $240 .{ }^{1} \mathrm{H}$ NMR $\left(300 \mathrm{MHz}, \mathrm{CDCl}_{3}\right): \delta 2.42\left(3 \mathrm{H}, \mathrm{s}, \mathrm{CH}_{3}\right), 3.93(3 \mathrm{H}, \mathrm{s}$, $\left.\mathrm{OCH}_{3}\right), 6.48(1 \mathrm{H}, \mathrm{s}, \mathrm{H}-2), 6.58(1 \mathrm{H}, \mathrm{s}, \mathrm{H}-7), 6.92(1 \mathrm{H}, \mathrm{s}, \mathrm{H}-$ 4), 7.12 (1H, s, H-5), 12.08 (1H, s, H-1), $12.28(1 \mathrm{H}, \mathrm{s}, \mathrm{H}-8) ;{ }^{13} \mathrm{C}$ $\operatorname{NMR}\left(75 \mathrm{MHz}, \mathrm{CDCl}_{3}\right): \delta 21.2\left(\mathrm{C}-2^{\prime}\right), 55.7\left(\mathrm{C}-3^{\prime}\right), 106.7(\mathrm{C}-5)$, 108.9 (C-7), 162.2 (C-1), 167.3 (C-6), 184.3 (C-10), 190.8 (C-9).

Compound 3. It is a white amorphous powder from $\mathrm{CDCl}_{3}$, $\mathrm{mp} 193-194^{\circ} \mathrm{C}$. The IR spectrum showed absorptions referring to a hydroxyl group $\left(3340 \mathrm{~cm}^{-1}\right)$ and carbonilic groups (1656 and $1619 \mathrm{~cm}^{-1}$, resp.). The EI mass spectrum of 3 displayed a molecular ion $[\mathrm{M}]^{+}$at $\mathrm{m} / z 254$ (100\%), which is in accordance with the molecular formula $\mathrm{C}_{15} \mathrm{H}_{10} \mathrm{O}_{5}$. Other major fragments were also observed at $\mathrm{m} / z 212,197,169$, and 43. ${ }^{1} \mathrm{H}$ NMR (300 MHz, $\left.\mathrm{CDCl}_{3}\right): \delta 2.47\left(3 \mathrm{H}, \mathrm{s}, \mathrm{CH}_{3}\right), 7.10(1 \mathrm{H}$, d, $J=1.1 \mathrm{~Hz}, \mathrm{H}-2), 7.31(1 \mathrm{H}, \mathrm{dd}, J=7.62,1.4 \mathrm{~Hz}, \mathrm{H}-7), 7.67(1 \mathrm{H}$, d, $J=1.1 \mathrm{~Hz}, \mathrm{H}-4), 7.70(1 \mathrm{H}, \mathrm{t}, J=8.0 \mathrm{~Hz}, \mathrm{H}-6), 7.85(1 \mathrm{H}, \mathrm{dd}$, $J=7.52,1.4 \mathrm{~Hz}, \mathrm{H}-5), 12.03$ (1H, s, H-1), $12.14(1 \mathrm{H}, \mathrm{s}, \mathrm{H}-8)$; ${ }^{13} \mathrm{C}$ NMR $\left(75 \mathrm{MHz}, \mathrm{CDCl}_{3}\right): \delta 22.4\left(\mathrm{C}-2^{\prime}\right), 113.7$ (C-13), 115.9 (C-12), 119.9 (C-5), 121.4 (C-4), 121.4 (C-7), 124.5 (C-2), 133.3 (C-14), 133.6 (C-11), 136.9 (C-6), 149.3 (C-3), 162.4 (C-1), 162.7 (C-8), 182.0 (C-10), 192.5 (C-9).

All three isolated compounds emodine (1), physcione (2), and chrysophanol (3) are well-known and were identified. In addition, these compounds also underwent spectroscopic analysis to compare the reported spectroscopic data. These compounds proved to be active against Gram-positive and Gram-negative microorganisms $[9,10]$, are very common in the genus Senna, and are known to have several biological activities, among them, remarkable antimicrobial activity [11]. The compounds were tested against $S$. aureus isolated strains, the main causative agent of bovine mastitis, and the obtained results are presented in Table 1 .

Results from Table 1 are in accordance with the information provided by local farmers that use this plant to treat bovine mastitis. The three isolated compounds showed good to excellent antimicrobial activities, ranging from 20 to 
TABLE 1: MIC $\left(\mu \mathrm{g} \mathrm{mL}^{-1}\right)$ values of compounds isolated from a dichloromethane extract of S. macranthera roots against S. aureus strains.

\begin{tabular}{lcccc}
\hline Microorganisms & & \multicolumn{3}{c}{ Compounds } \\
& Emodine (1) & Physcione (2) & Chrysophanol (3) & Ciclopirox olamine \\
\hline S. aureus 3828 & 60 & 120 & 190 & 50 \\
S. aureus 4125 & 20 & 90 & 90 & 50 \\
S. aureus 4158 & 40 & 100 & 190 & 50 \\
\hline
\end{tabular}

TABLE 2: Antibacterial activity of the dichloromethane and ethanol extracts from S. macranthera roots against Staphylococcus aureus strains.

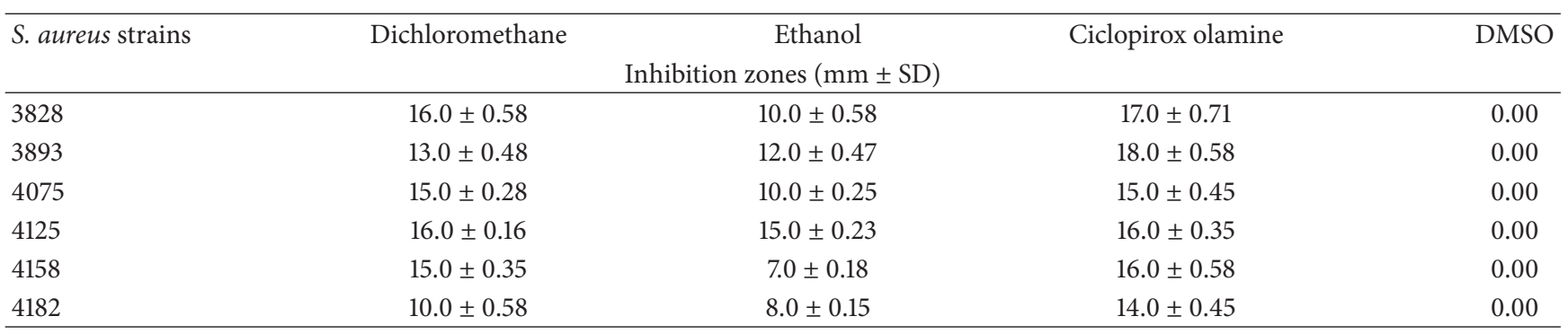

$190 \mu \mathrm{g} \mathrm{mL}^{-1}$, and are most likely responsible for the antimicrobial activity observed with the tested dichloromethane extract.

Similarly, as can be seen in Table 2, both dichloromethane and ethanol extracts showed good activity in combatting $S$. aureus, the main causative agent of bovine mastitis. Likewise, the same extracts also showed positive activity against other microorganisms, such as Streptococcus agalactiae, Streptococcus bovis, and Escherichia coli (Table 3), which are also causative agents of this disease.

According to Table 3, the dichloromethane extract can be considered more active than an ethanol extract against the tested bacteria, except for E. coli, whose activity was lower.

As the two extracts showed significant antibacterial activity against the three tested bacteria, the MIC have been made with all of them (Table 4). The attained MIC values of the most active dichloromethane extract against the tested bacteria proved to be better when compared to that previously found from other extracts of plants with antimicrobial activities [12, 13]. According to Aligiannis criteria [14], the dichloromethane extract can be considered strong inhibitors for $S$. aureus and S. agalactiae and moderate for S. bovis. Hence, the ethanol extract can be considered moderate for the three tested microorganisms (Table 4).

Several studies have shown that biofilm formation is a key factor in the establishment and persistence of infections caused by $S$. aureus and S. agalactiae in animals with mastitis infection [15]. Currently, no vaccines or immunotherapies have been approved to treat these Staphylococcal infections. This area of research has peaked considerable interest, mainly for the use of small molecules to combat staphylococcal biofilms [16]. Thus, the dichloromethane and ethanol extracts were tested in subinhibitory concentrations of MIC values $(1 / 2,1 / 4,1 / 8$, and $1 / 16)$ to evaluate $\mathrm{BIC}$ and adhesion on preformed biofilms against these microorganisms. The results showed that the dichloromethane extract presented the lowest BIC values for $S$. aureus and $S$. agalactiae, equal to $1 / 8$ and $1 / 2$, respectively, of the obtained MIC values. For the ethanol extract, the BIC values were $1 / 4$ and $1 / 2$ on $S$. aureus and $S$. agalactiae, respectively (Table 5).

According to Table 5, the best BIC value $\left(0.063 \mathrm{mg} \mathrm{mL}^{-1}\right)$ obtained for the dichloromethane extract against $S$. aureus can indicate that this extract can inhibit bacterial film formation in the initial phase of adhesion and formation of biofilms. This value was similar to those found for antibiotic substances reported in prior literature [8].

Due to the promising results concerning the antibacterial activities of active extracts from $S$. macranthera roots and compounds isolated through biomonitoring, according to the above discussion, the authors of this study were encouraged to prepare an herbal soap containing the active extract. As a result, the herbal soaps should represent a new alternative that is easily accessible for use by farmers from small farms in the rural areas of Brazil who already use this plant in an attempt to control bovine mastitis. For this purpose, a new procedure was devised for antibacterial tests. The herbal soap was tested in vivo, using gloves that had been contaminated by animals with bovine mastitis and that had been discarded after having been used by the milkers of the university's bovine culture sector.

Figure 2 showed that the herbal soap obtained from the most active dichloromethane extract of the $S$. macranthera roots reduces the bacterial load to $79.0 \pm 4.0 \mathrm{CFU}$. This result is in agreement with those observed by small farmers.

Figure 3 shows the results observed in the in vivo evaluation with the milkers' discarded gloves immersed or not in the $1 \%$ suspension of herbal soap together with an active extract of S. macranthera. Figure 3(a) showed the microbial growth in the Petri dishes in which the gloves were not immersed in the herbal soap suspension. By contrast, Figure 3(b) showed no microbial growth in the Petri dishes after the milkers' discarded gloves had been immersed for $30 \mathrm{~min}$ in the herbal soap suspension.

The results obtained from in vivo tests (Figure 3) suggested that the active extract of this plant can be incorporated 
TABLE 3: Antibacterial activity of the dichloromethane and ethanol extracts against Streptococcus agalactiae (3849), Streptococcus bovis (550), and Escherichia coli (24) strains.

\begin{tabular}{lccc}
\hline Extracts & & Microorganisms \\
& S. agalactiae (3849) & $\begin{array}{c}\text { S. bovis (550) } \\
\text { Inhibition zones } \pm \text { SD (mm) }\end{array}$ & E. coli (24) \\
\hline Dichloromethane & & $8.0 \pm 0.20$ & $1.3 \pm 0.30$ \\
Ethanol & $15.0 \pm 0.28$ & $4.0 \pm 0.36$ & $2.0 \pm 0.28$ \\
Ciclopirox olamine $^{*}$ & $10.0 \pm 0.52$ & $18.0 \pm 0.20$ & $18.0 \pm 0.47$ \\
DMSO $^{* *}$ & $15.0 \pm 0.38$ & 0.00 & 0.00 \\
\hline
\end{tabular}

${ }^{*}$ Positive control. ${ }^{* *}$ Negative control.

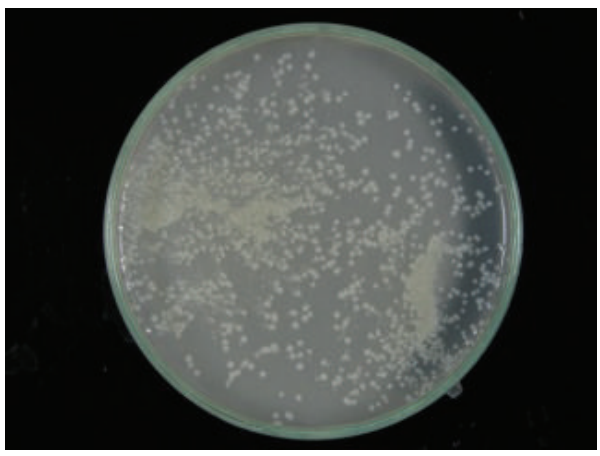

(a) Control

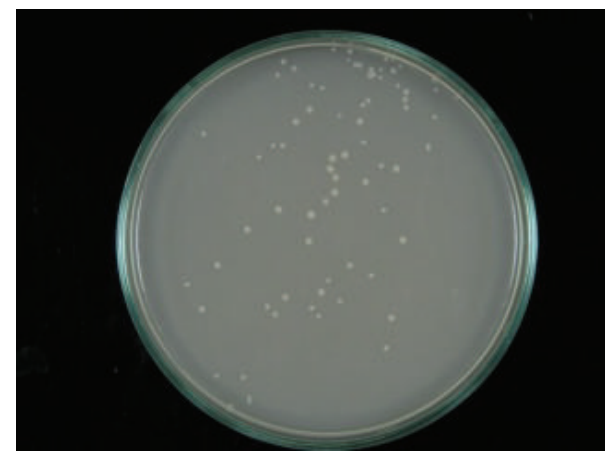

(b) Soap of S. macranthera $79.0 \pm 4.0$ UFC

FIGURE 2: In vitro antibacterial activities of herbal soap produced with the most active extract of $S$. macranthera. Tests were performed in triplicate.

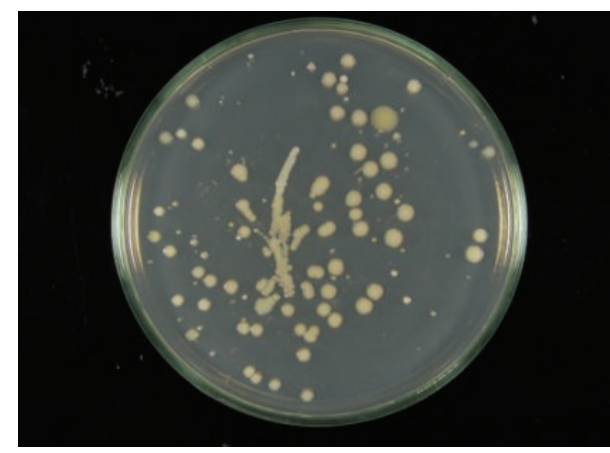

(a) Result without immersing milkers' discarded gloves in herbal soup

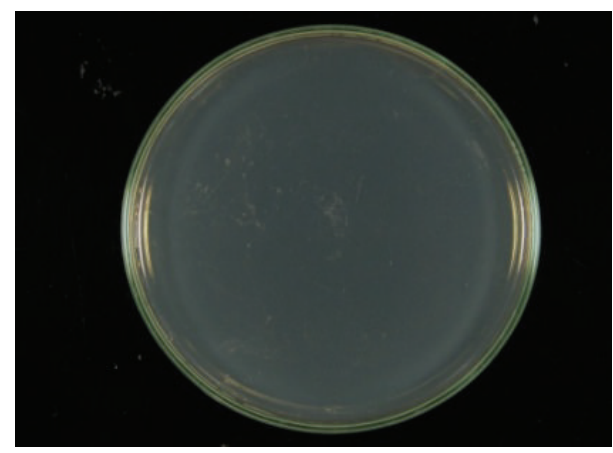

(b) Result after milkers' discarded gloves were immersed in S. macranthera herbal soap

FIGURE 3: In vivo antibacterial activities of herbal soap with the active extract of Senna macranthera and the milkers' discarded gloves.

into herbal soaps that aimed at cleaning the animals' udders before milking, especially in small farms.

\section{Conclusion}

In summary, the inhibitory effects of the active extract of $S$. macranthera against $S$. aureus strains can be attributed to anthraquinone compounds $\mathbf{1}, \mathbf{2}$, and $\mathbf{3}$, found in the roots of this plant. The activity of the dichloromethane extract may well be associated with the synergism among the isolated compounds and other compounds that have not yet been isolated from this plant. Nevertheless, the herbal soap produced with an active extract of $S$. macranthera demonstrated a high inhibition against $S$. aureus, when the milkers' discarded gloves were immersed in the $1 \%$ suspension of herbal soap, indicating the potential of this plant as an excipient in the production and use of antiseptic soaps to control bovine mastitis infections, especially in small farms.

\section{Conflict of Interests}

The authors declare that there is no conflict of interests regarding the publication of this paper. 
TABLE 4: MIC $\left(\mathrm{mg} \mathrm{mL}^{-1}\right)$ values of activity extracts from S. macranthera roots against $S$. aureus, S. agalactiae, and S. bovis.

\begin{tabular}{lcc}
\hline Microorganisms & Extract & MIC \\
\hline & Dichloromethane & 0.5 \\
S. aureus (3828) & Ethanol & 1.0 \\
& Positive control & 0.05 \\
\hline \multirow{3}{*}{ S. agalactiae (3849) } & Dichloromethane & 0.6 \\
& Ethanol & 0.8 \\
& Positive control & 0.05 \\
S. bovis (550) & Dichloromethane & 0.8 \\
& Ethanol & 1.0 \\
& Positive control & 0.05 \\
\hline
\end{tabular}

TABLE 5: BIC $\left(\mathrm{mg} \mathrm{mL}^{-1}\right)$ values of the dichloromethane and ethanol extracts against $S$. aureus and $S$. agalactiae bacteria.

\begin{tabular}{lcc}
\hline Extracts & Microorganisms & BIC \\
\hline \multirow{3}{*}{ Dichloromethane } & S. aureus $(3828)$ & 0.063 \\
& S. agalactiae (3849) & 0.3 \\
& Positive control & 0.025 \\
\hline \multirow{2}{*}{ Ethanol } & S. aureus (3828) & 0.25 \\
& S. agalactiae (3849) & 0.4 \\
& Positive control & 0.025 \\
\hline
\end{tabular}

\section{Acknowledgments}

The authors are grateful to CAPES for scholarships awarded to Flávia Andrade Inoue and Thalita de Faria Maia, to $\mathrm{CNPq}$ for their financial support (470153/2011-3), and Embrapa Gado do Leite, Juiz de Fora, Minas Gerais, who kindly provided the bacterial strains.

\section{References}

[1] C. C. Rossi, A. P. Aguilar, M. A. N. Diaz, and A. D. O. B. Ribon, "Aquatic plants as potential sources of antimicrobial compounds active against bovine mastitis pathogens," African Journal of Biotechnology, vol. 10, no. 41, pp. 8023-8030, 2011.

[2] F. B. Holetz, G. L. Pessini, N. R. Sanches, D. A. G. Cortez, C. V. Nakamura, and B. P. Dias Filho, "Screening of some plants used in the Brazilian folk medicine for the treatment of infectious diseases," Memorias do Instituto Oswaldo Cruz, vol. 97, no. 7, pp. 1027-1031, 2002.

[3] K. S. Almeida and F. L. C. Freitas, "Etnoveterinária: a fitoterapia na visão do futuro profissional veterinário," Revista Verde, vol. 1, no. 1, pp. 67-74, 2006.

[4] M. M. Cowan, "Plant products as antimicrobial agents," Clinical Microbiology Reviews, vol. 12, no. 4, pp. 564-582, 1999.

[5] C. Viegas Jr., A. de Rezende, D. H. S. Silva et al., "Aspectos químicos, biológicos e etnofarmacológicos do gênero Cassia," Química Nova, vol. 29, no. 6, pp. 1279-1286, 2006.

[6] A. K. Gupta and T. Plott, "Ciclopirox: a broad-spectrum antifungal with antibacterial and anti-inflammatory properties," International Journal of Dermatology, vol. 43, no. 1, pp. 3-8, 2004.
[7] A. Nostro, A. S. Roccaro, G. Bisignano et al., "Effects of oregano, carvacrol and thymol on Staphylococcus aureus and Staphylococcus epidermidis biofilms," Journal of Medical Microbiology, vol. 56, no. 4, pp. 519-523, 2007.

[8] M. A. N. Diaz, "Composições domissaneantes à base de óleo de macaúba e extratos de Salvinia auriculata e seus derivados com ação terapêutica e seu uso para prevenção e/ou controle de mastite bovina," BR PI1103394-0, Patent, 2012.

[9] R. M. Coopoosamy and M. L. Magwa, "Antibacterial activity of chrysophanol isolated from Aloe excelsa (Berger)," African Journal of Biotechnology, vol. 5, no. 16, pp. 1508-1510, 2006.

[10] Y. M. Kim, C. H. Lee, H. G. Kim, and H. S. Lee, "Anthraquinones isolated from Cassia tora (Leguminosae) seed show an antifungal property against phytopathogenic fungi," Journal of Agricultural and Food Chemistry, vol. 52, no. 20, pp. 6096-6100, 2004.

[11] M. A. N. Diaz, C. C. Rossi, V. R. Mendonça et al., "Screening of medicinal plants for antibacterial activities on Staphylococcus aureus strains isolated from bovine mastitis," Brazilian Journal of Pharmacognosy, vol. 20, no. 5, pp. 24-28, 2010.

[12] M. C. T. Duarte, G. M. Figueira, B. Pereira, P. M. Magalhães, and C. Delarmelina, "Atividade antimicrobiana do extrato de Anacardium occidentale Linn. em amostras multiresistentes de Staphylococcus aureus," Revista Brasileira de Farmacognosia, vol. 14, no. 1, pp. 6-8, 2004.

[13] S. Virtuoso, A. Davet, J. F. G. Dias et al., "Estudo preliminar da atividade antibacteriana das cascas de Erythrina velutina Willd., Fabaceae (Leguminosae)," Brazilian Journal of Pharmacognosy, vol. 15, no. 2, pp. 137-142, 2005.

[14] N. Aligiannis, E. Kalpoutzakis, S. Mitaku, and I. B. Chinou, "Composition and antimicrobial activity of the essential oils of two Origanum species," Journal of Agricultural and Food Chemistry, vol. 49, no. 9, pp. 4168-4170, 2001.

[15] Y. K. Ghiorghi, E. Mairey, A. Mallet et al., "Dual role for pilus in adherence to epithelial cells and biofilm formation in Streptococcus agalactiae," PLoS Pathogens, vol. 5, pp. 412-422, 2009.

[16] M. García-Castillo, M. I. Morosini, A. Valverde et al., "Differences in biofilm development and antibiotic susceptibility among Streptococcus pneumoniae isolates from cystic fibrosis samples and blood cultures," Journal of Antimicrobial Chemotherapy, vol. 59, no. 2, pp. 301-304, 2007. 


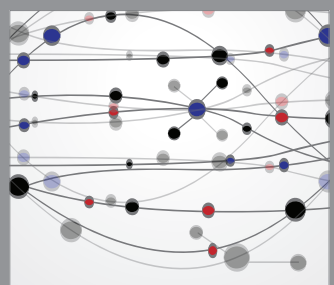

The Scientific World Journal
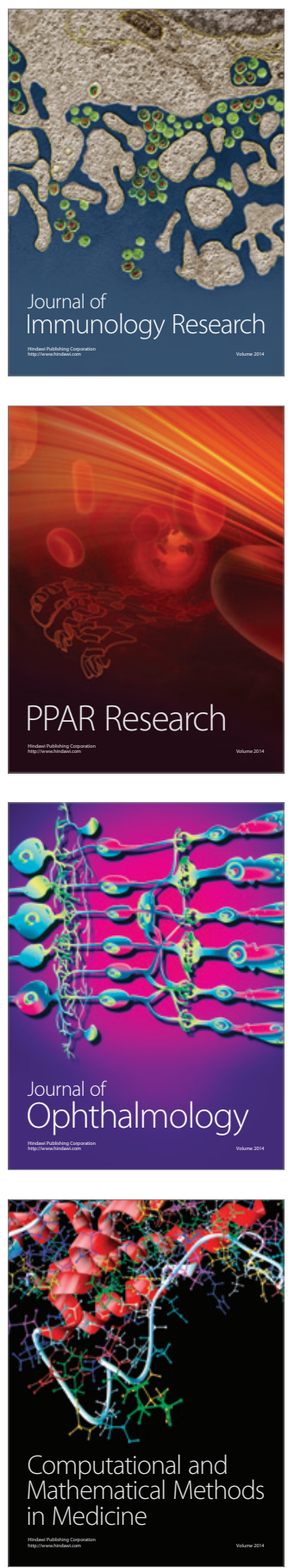

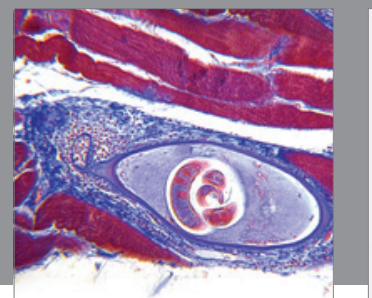

Gastroenterology

Research and Practice
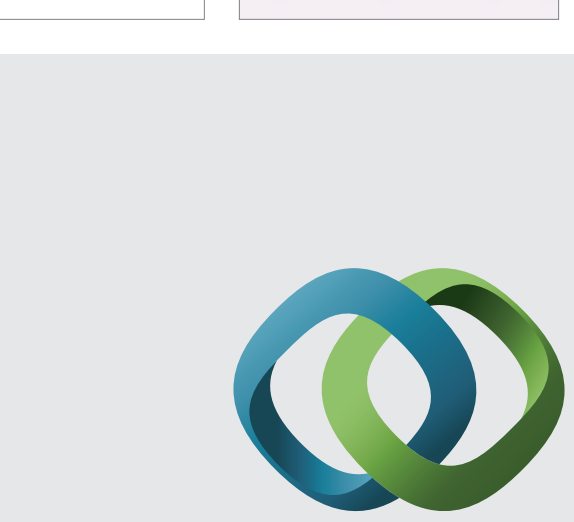

\section{Hindawi}

Submit your manuscripts at

http://www.hindawi.com
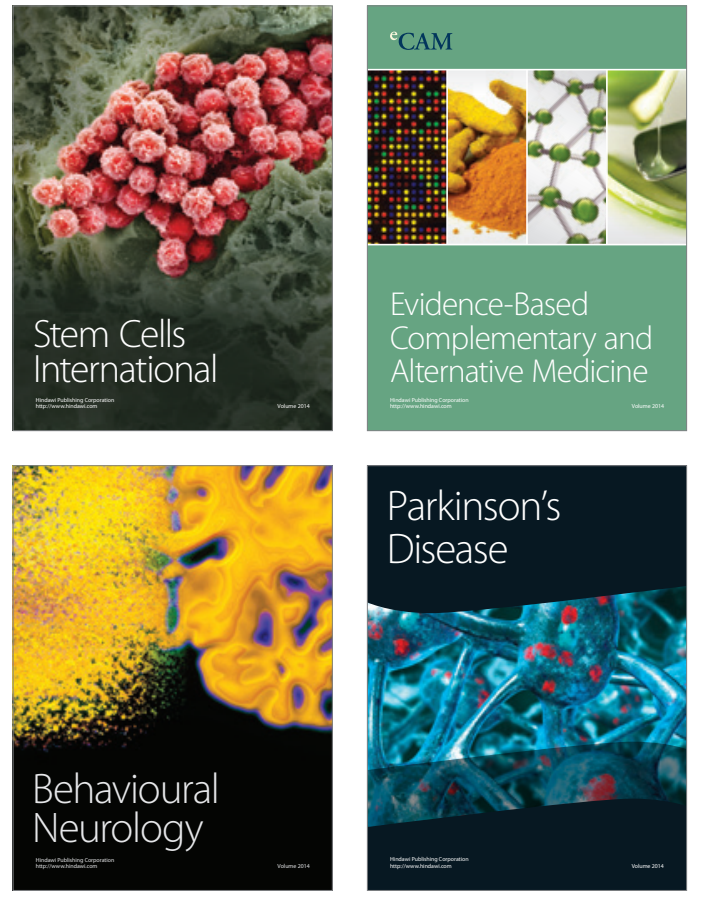
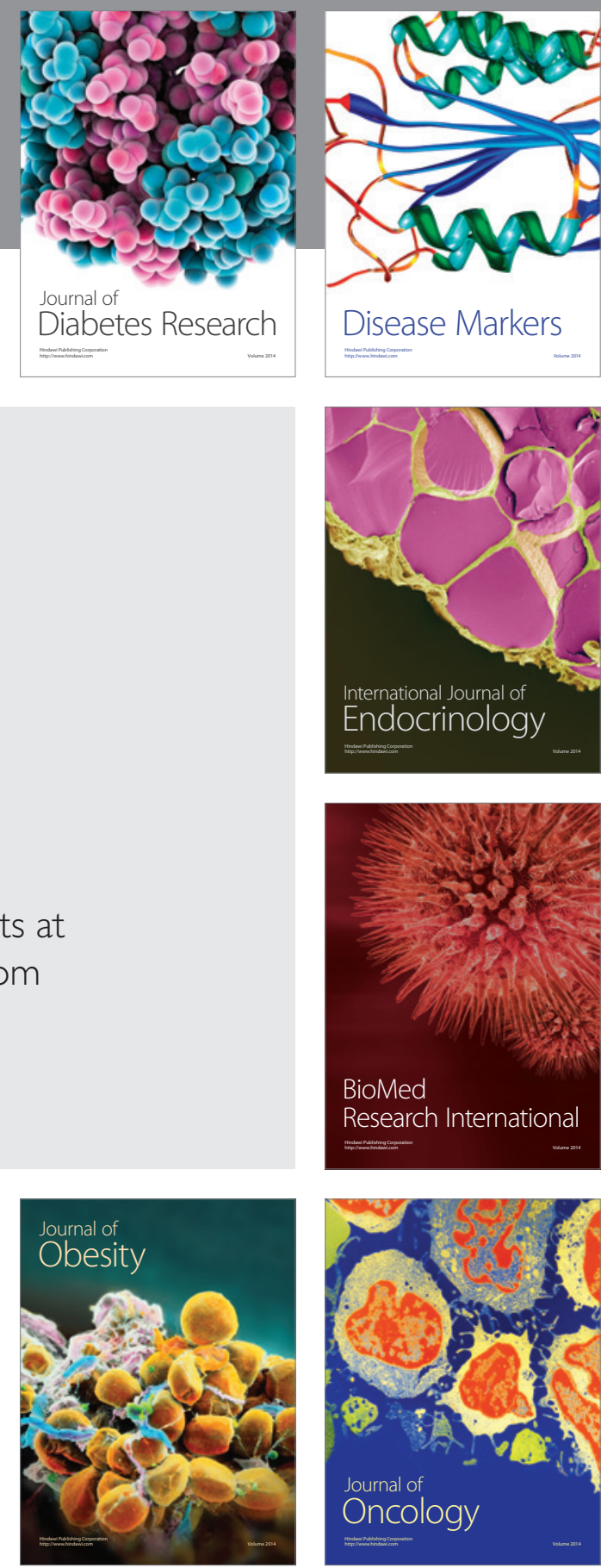

Disease Markers
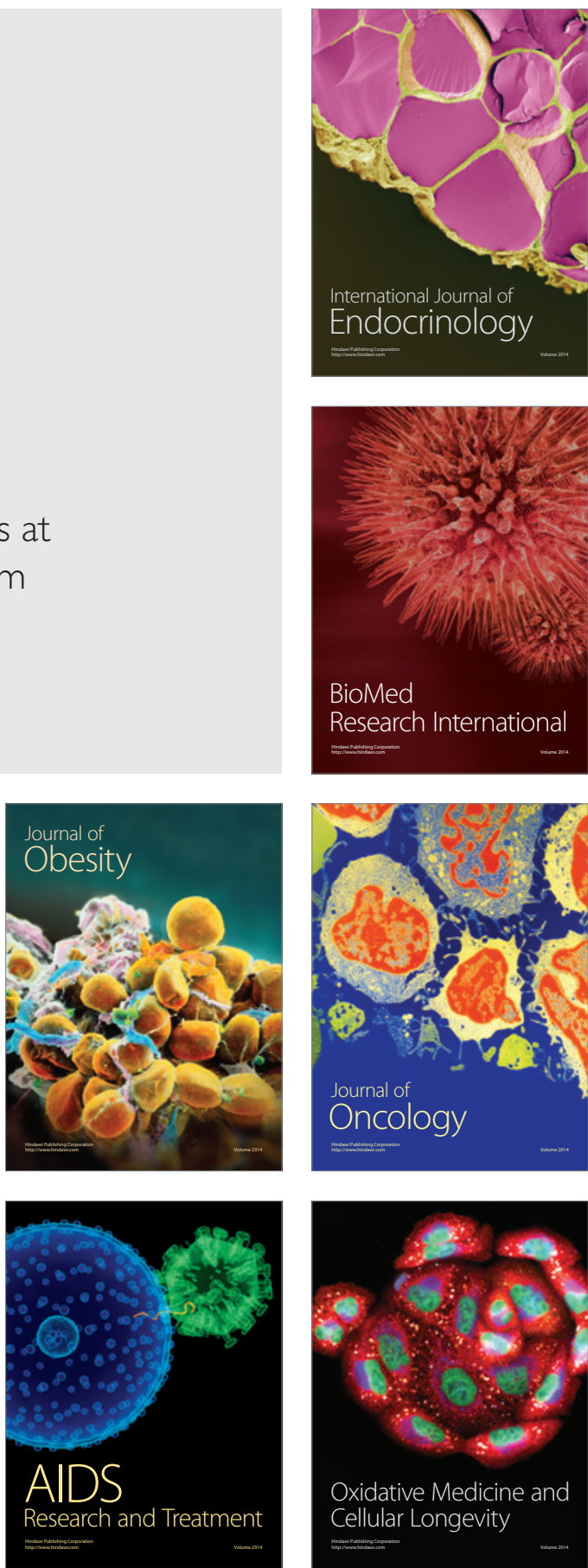